EPJ Web of Conferences 82, 01045 (2015)

DOI: $10.1051 /$ epjconf/20158201045

(C) Owned by the authors, published by EDP Sciences, 2015

\title{
Ignition of a coal particle at the low temperature of gas flow
}

\author{
Dmitrii O. Glushkov ${ }^{1, a}$ and Oleg V. Sharypov² \\ ${ }^{1}$ National Research Tomsk Polytechnic University, 634050 Tomsk, Russia \\ ${ }^{2}$ Kutateladze Institute of Thermophysics, Siberian Branch, Russian Academy of Sciences, \\ 630090 Novosibirsk, Russia
}

\begin{abstract}
Regularities of physical and chemical processes occurring during the heating of the coal dust particles by low-temperature air flow are investigated by means of thermogravimetric analyzer TA SDT Q600 and experimental setup of optical diagnostics of multiphase flows based on PIV method. Qualitative and quantitative characteristics were established for the processes of the coal particle inert heating, moisture evaporation, thermal decomposition, combustible gas mixture formation, oxidation of volatiles and carbon. It was revealed that the temperature of the oxidizer required for the coal particle ignition is higher than $500{ }^{\circ} \mathrm{C}$. The experimental data can be used to develop predictive mathematical models of technological processes fire hazard in pulverized coal systems of thermal power plants.
\end{abstract}

\section{Introduction}

According to the latest trends in the global energy industry, there are several areas to increase production capacity. These directions are primarily characterized by types of energy sources: fission and fusion energy sources, alternative energy sources (water, wind, solar, geo-energy), traditional energy sources (solid, liquid and gaseous fossil fuels).

The share of nuclear and alternative energy sources in the total world energy is too low and does not exceed $15 \%$. The reason can be explained as follows. Firstly, the processes of nuclear thermal power plants are extremely complex and are potentially dangerous to the environment and humans. Secondly, most of the alternative energy sources are not capable of energy generating on an industrial scale. Thirdly, the current level of science and technology development cannot create a fundamentally new technology and equipment for more efficient and safe conversion of energy into heat and electricity.

Therefore, the traditional energy sources have great potential for development and modernization in the near future. Especially coal-fired thermal power plants should be allocated because according to experts estimate the world reserves of solid fuels exceed the total reserves of oil and natural gas. In the long term both problems of increasing the efficiency of industrial production and prevention of accidents deserve the special attention of specialists. Increasing of safety of the energy production technological process is relevant for the newly introduced into commercial operation and for modernized thermal power plants. Pulverized coal systems are more susceptible to accidents leading to serious consequences,

\footnotetext{
${ }^{\text {a }}$ Corresponding author: dmitriyog@tpu.ru
}

This is an Open Access article distributed under the terms of the Creative Commons Attribution License 4.0, which permits unrestricted use, distribution, and reproduction in any medium, provided the original work is properly cited. 
both on an individual station, and across the grid. It is largely due to the high susceptibility of existing technologies of fuel preparation even slight changes to the environmental conditions (temperature, humidity, pressure, electromagnetic field).

The purpose of the present work is an experimental study of physical and chemical processes during heating the coal dust particles by low-temperature air stream.

\section{Characteristics of the experimental sample}

The object of investigation was selected lignite Kansk-Achinsk coal basin, which is widely used as a fuel in thermal power plants of the largest regions of the Russian Federation (Krasnoyarsk Territory, Republic of Khakassia, and Irkutsk Region). Samples of pulverized coal were obtained by pulverizing of a solid fossil fuel large particle using a ball mill. About $80 \%$ of coal particles in a polydisperse mixture of the sample did not exceed $200 \mu \mathrm{m}$. The choice of this size is due to three factors:

1. Maximum homogeneity of the coal dust for the reproducibility of fuel thermal parameters in a series of experiments.

2. Application of coarse fraction coal dust (particle size greater than $200 \mu \mathrm{m}$ ) leads to incomplete combustion of fuel in boiler furnace.

3. The production process of fine coal dust (particle size less than $200 \mu \mathrm{m}$ ) is easily combusted in the boiler furnaces is characterized by high energy costs.

\section{Experimental studies and results}

The study of the processes occurring during the heating of coal dust was carried out using a thermogravimetric analyzer TA SDT Q600. The mass of samples was about $20 \mathrm{mg}$. A series of experiments were carried out in an atmosphere of air and inert gas (argon). Heating of the samples was performed at $5 \% \mathrm{~min}$. Thermogravimetric analysis (Fig. 1) showed that the sample contained moisture $7.74 \%$, volatiles $26.69 \%$, carbon $53.26 \%$, and inorganic part $12.31 \%$.

When heating the sample evaporation of moisture occurred in the temperature range from 20 to $105^{\circ} \mathrm{C}$. The heat effect of endothermic phase transition was about $650 \cdot 10^{3} \mathrm{~J} / \mathrm{kg}$. By further heating the sample thermal decomposition of coal occurs in two stages (Fig. 1b): during the first stage combustible gas evolution was observed from the coal dust surface. Until the completion of the first stage, the thermal decomposition process was transformed into the next one with the formation of elemental carbon (Fig. 1b). During the second stage, resulting in uniform heating of coal particles, residue of organic components was blown to the gas mixture. Intensive gas evolution was observed in the temperature range from 120 to $400^{\circ} \mathrm{C}$. The heat effect of the thermal decomposition process with heat absorption was about $90 \cdot 10^{3} \mathrm{~J} / \mathrm{kg}$. The combustion process of coal also occurred in two stages (Fig. 1a): in the first stage interaction of atmospheric oxygen with a combustible gas mixture was observed at the temperature about $300^{\circ} \mathrm{C}$. Until the completion of the first stage, the combustion process was transformed into the second stage. Burning spreads in volume of elemental carbon. As a result inorganic part was formed. Intensive carbon burning velocity was observed in the temperature range from 400 to $500{ }^{\circ} \mathrm{C}$. The heat effect of the exothermic oxidation reaction was about $12 \cdot 10^{6} \mathrm{~J} / \mathrm{kg}$.

Other experimental investigation with using the setup (Fig. 2) for optical diagnostics of multiphase flows based on the PIV method [1,2] was carried out for the analysis of the ignition delay time values in a real technological process conditions and a more detailed study of heat and mass transfer in the vicinity of the coal particles.

The main elements of the installation the following: double pulsed solid-state laser 1 and 2 with active "yttrium aluminum garnet" sphere and neodymium additives (wave-length $532 \cdot 10^{-9} \mathrm{~m}$, energy in impulse not less than $70 \cdot 10^{-3} \mathrm{~J}$, impulse time not more than $12 \cdot 10^{-9} \mathrm{~s}$, recurrence frequency not more than $15 \mathrm{~Hz}$ ), cross-correlation digital camera 3 (figure format $2048 \times 2048$ pixels, frame frequency 
Thermophysical Basis of Energy Technologies

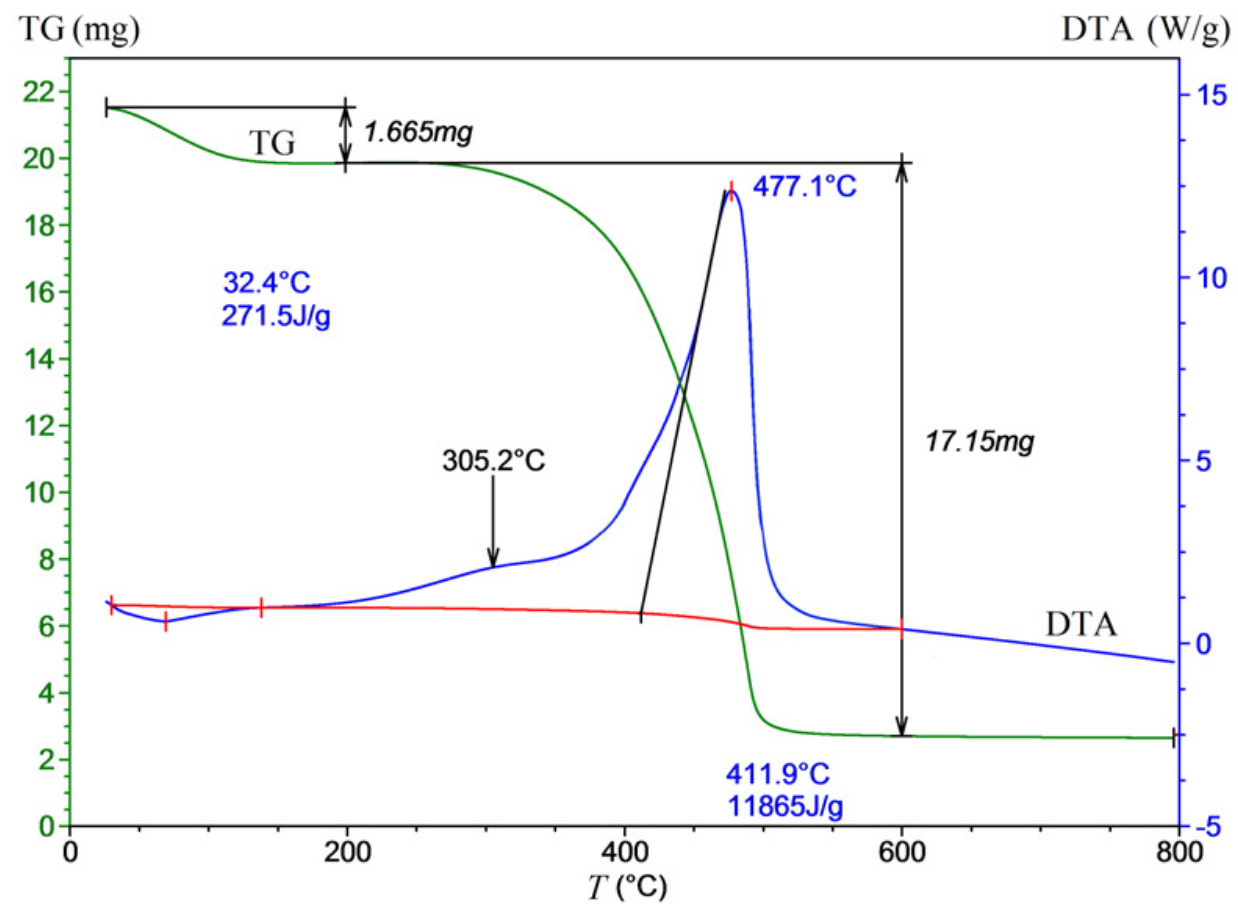

(a)

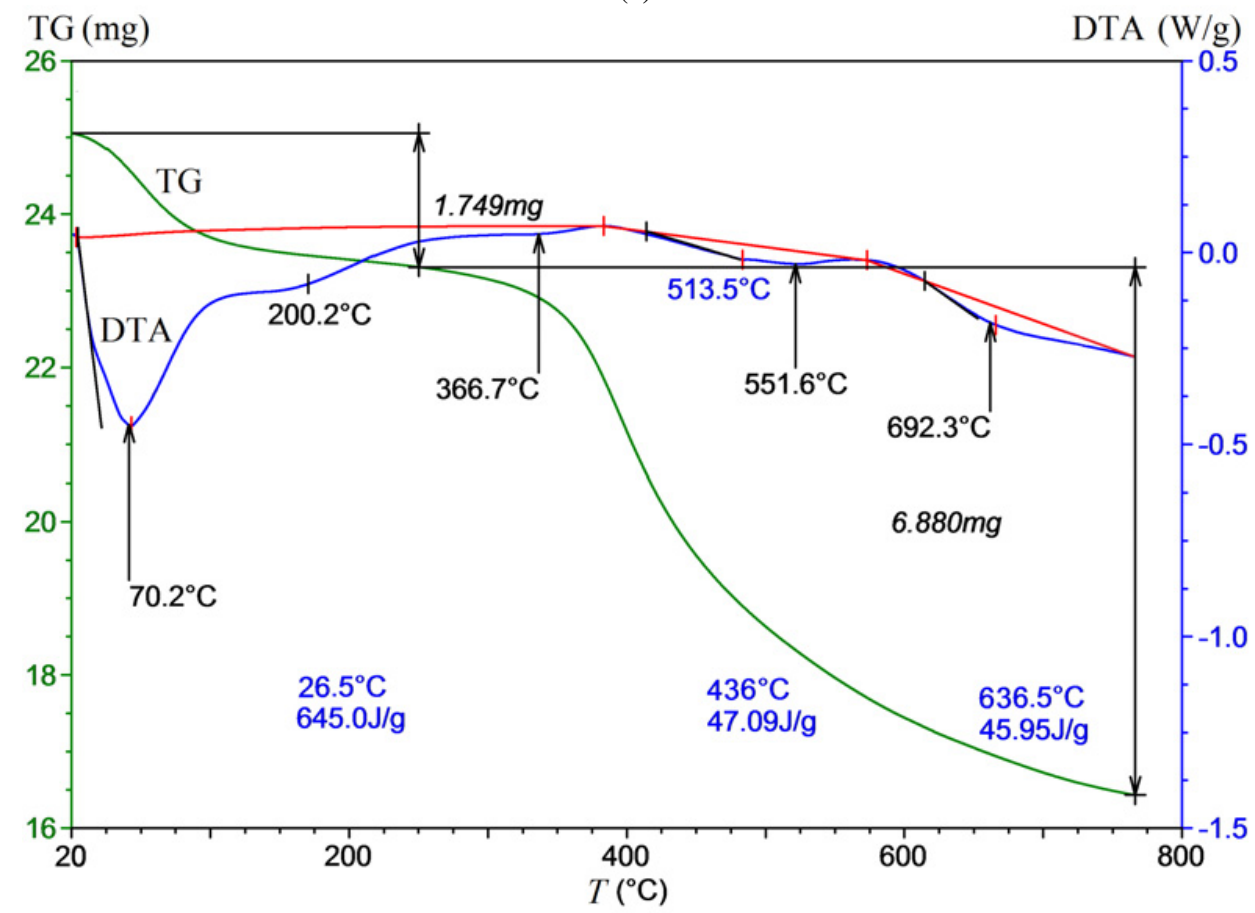

(b)

Figure 1. Curves of TG-DTA by heating samples of coal dust in air (a) and argon (b). 


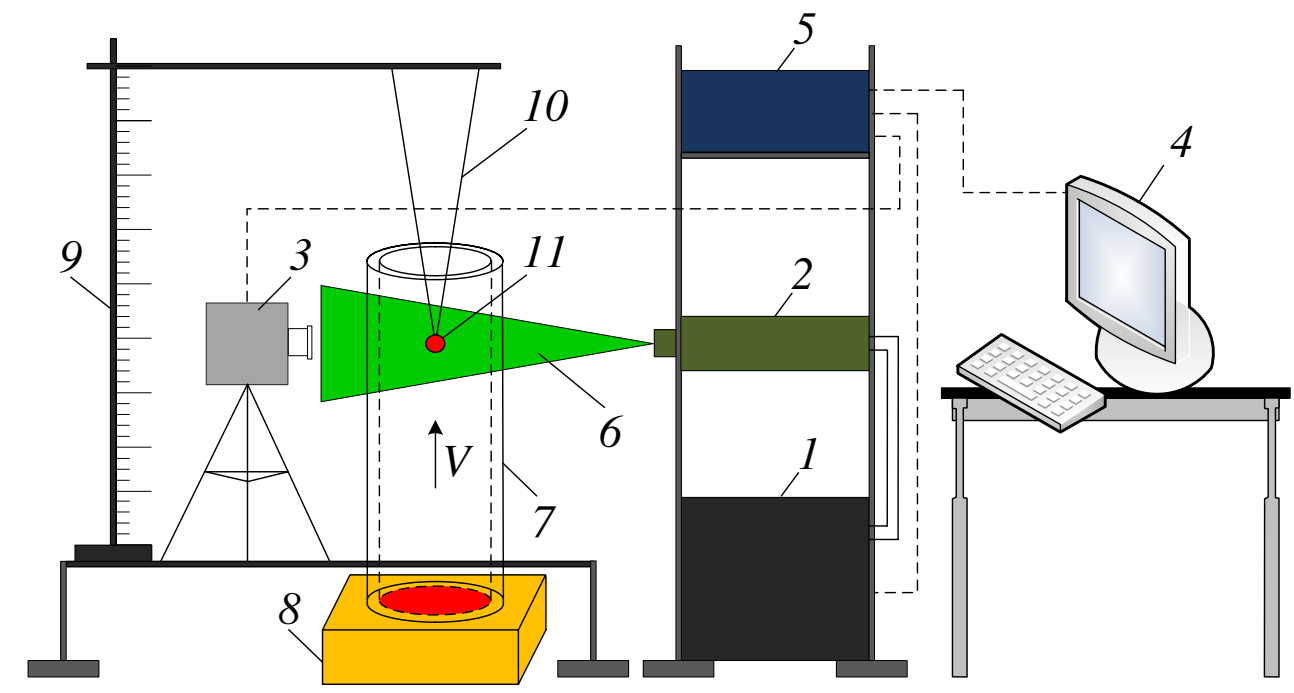

Figure 2. A scheme of experimental setup: 1 is a laser emission generator; 2 is a double pulsed solid-state laser; 3 is a cross-correlation digital camera; 4 is a personal computer; 5 is a synchronizer of personal computer, crosscorrelation digital camera and laser; 6 is a light pulse; 7 is a cylinder from a transparent heat-resistant material; 8 is a heat flux generator; 9 is a mount; 10 is a bracket; 11 is a coal particle.

not less than $1.5 \mathrm{~Hz}$, minimal delay between two sequence figures not more than $5 \cdot 10^{-6} \mathrm{~s}$ ), personal computer 4 with specialized software Actual Flow, synchronizing processor 5 (signal sampling not more than $10^{-8} \mathrm{~s}$ ), heating furnace 8 with adjustable parameters of the heat flux (temperature from 50 to $600{ }^{\circ} \mathrm{C}$, flow velocity from 0.5 to $5 \mathrm{~m} / \mathrm{s}$ ).

When planning the experiment the following scheme of the investigated process was adopted [3]. The coal particle 11 was fixed on the axis of symmetry of the cylinder 7 (Fig. 2) after blowing hot air through the hollow cylinder to establish a uniform distribution of temperature and velocity in air flow. The temperature was varied in the range from 200 to $600{ }^{\circ} \mathrm{C}$ and flow rate was constant $1 \mathrm{~m} / \mathrm{s}$ during determination of ignition process integral characteristics. Thermal decomposition of coal is achieved in a heating process. Products of gas evaluation (volatiles) mixed with an oxidizer through the mechanism of diffusion and convection mass transfer. A combustible gas mixture formed in the particle vicinity. Ignition occurred in the gas mixture due to reaching sufficient for ignition of temperatures and concentrations of the gaseous products of thermal decomposition. The time interval from the start of heating coal particle in the cylinder 7 to the appearance of the flame was recorded by the camera 3 and detected in the personal computer 4 (Fig. 2). The value of this time interval determined the ignition delay time $t_{d}$.

The PIV measurement system was used to visualize the flow of the gas mixture in the vicinity of the particle (laser emission generator 1 , double pulsed solid-state laser 2, cross-correlation digital camera 3 , personal computer 4 and synchronizer 5 of personal computer, cross-correlation digital camera and laser). Region translucence 6 in the vicinity of the particle 11 was performed using double pulsed solidstate laser 1 and 2 . Images of the gas mixture velocity fields were recorded in synchronization 5 modes of pulsed laser 1 and 2, cross-correlation digital camera 3 and personal computer 4 . For this purpose blowing of titanium dioxide nanopowder particles was carried [4-6] to the plane of the lower opening of the cylinder 7. Specialized software Actual Flow was used to process the output video.

Limit values of air temperature were established in experimental studies $\left(T_{\min }\right)$ at which ignition of coal particles with sizes $r=50-500 \mu \mathrm{m}$ is realized (Table 1). Also, the ignition delay times of coal particles are defined at the temperature $T=600^{\circ} \mathrm{C}$ of external gas area (Table 1). 
Table 1. Critical oxidizer temperatures $T_{\min }$ and ignition delay times of coal particles $t_{d}$ (at $T=600^{\circ} \mathrm{C}$ ).

\begin{tabular}{|l|l|l|l|l|l|l|l|l|l|l|}
\hline$r, \mu \mathrm{m}$ & 50 & 100 & 150 & 200 & 250 & 300 & 350 & 400 & 450 & 500 \\
\hline$T_{\min },{ }^{\circ} \mathrm{C}$ & 600 & 592 & 584 & 577 & 571 & 567 & 563 & 560 & 557 & 554 \\
\hline$t_{d}, \mathrm{~s}$ & 6.1 & 6.5 & 7.0 & 7.2 & 9.9 & 11.8 & 13.0 & 16.5 & 19.1 & 21.9 \\
\hline
\end{tabular}

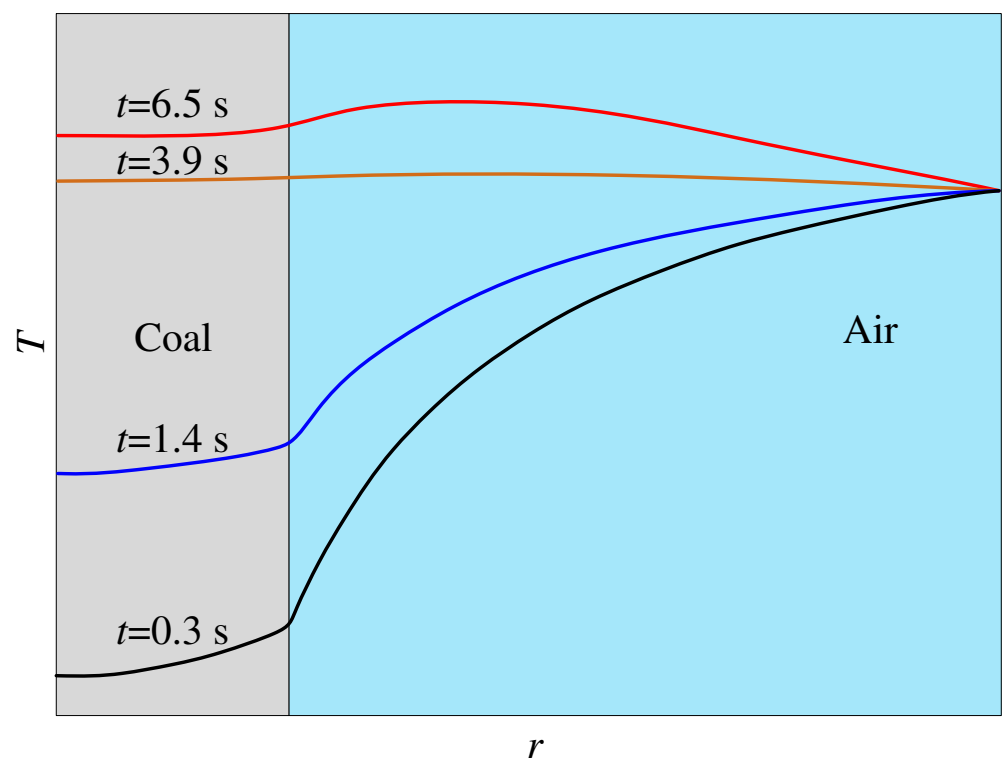

Figure 3. Temperature distribution in the vicinity of the coal particle with $r=100 \mu \mathrm{m}$ and $T=600{ }^{\circ} \mathrm{C}$ at different time points.

Figure 3 shows the temperature distribution in the "coal particle - oxidizer" system at different time points of the induction period. It is evident that a large quantity of energy is absorbed during the process of coal thermal decomposition. It leads to a decrease of air temperature in the vicinity of the particle. The heat release accelerates nonlinearly during the oxidation reaction due to the increasing of combustible gas concentration. It leads to an increasing of temperature at the "coal particle - oxidizer" border and acceleration of the warming of the particle deep layers. The growth of the gas mixture oxidation rate is accompanied by a decrease of the combustible gas concentration in the exothermic reaction area. Ignition occurs in the gas mixture due to reaching sufficient for ignition of temperatures and concentrations of the gaseous products of thermal decomposition.

The collection of data on critical oxidizer temperatures and ignition delay times of coal particles (Table 1) can be used to assess the potential danger of the coal dust heating process in the real technological process. Maximum values of $t_{d}$ for particles with sizes $r=50-500 \mu \mathrm{m}$ do not exceed $22 \mathrm{~s}$ (Table 1). The obtained values of ignition ignition times at a relatively low temperature of air allow to explain the possible causes of fires and accidents in the different aggregates and systems of thermal power engineering objects (e.g., in pulverized coal systems). In particular, coal dust can be in the conditions of the oxidizer area with a temperature over $500^{\circ} \mathrm{C}$ for a time substantially greater than $t_{d}$ during preparation of fuel for combustion in boiler furnace. Given the polydisperse composition of coal dust implementation of ignition conditions at least one particle initiates the ignition of other particles in its vicinity. 


\section{Conclusions}

The regularities and characteristics of physical and chemical processes that occur during heating of the coal dust particles by low-temperature air flow were established as a result of experimental studies. It was revealed that the temperature of the oxidizer required for the ignition of the coal particles in case of technological process is not less than $500{ }^{\circ} \mathrm{C}$. Quantitative results can be used to develop predictive models of fire hazard processes in pulverizing coal systems of thermal power plants.

The reported study was supported by the RFBR (project No. 14-38-50003 mol_nr).

\section{References}

[1] G.V. Kuznetsov, P.A. Strizhak, High Temperature 52, 568 (2014)

[2] G.V. Kuznetsov, P.A. Strizhak, Technical Physics Letters 40, 499 (2014)

[3] D.O. Glushkov, P.A. Strizhak, O.V. Vysokomornaya, Thermal Science, DOI: $10.2298 / \mathrm{TSCI} 140521107 \mathrm{G}$

[4] C.E. Willert, M. Gharib, Experiments in Fluids 10, 181 (1991)

[5] M. Raffel, C. Willert, J. Kompenhans, Particle image velocimetry (Springer Verlag, Berlin, 1998)

[6] J. Westerweel, Measurement Science and Technology 8, 1379 (1997) 